\title{
O ensino da promoção da saúde na graduação de fonoaudiologia na cidade de São Paulo
}

\author{
Isis Alexandrina Casanova*, Ana Alcídia de Araújo Moraes ${ }^{* *}$ e Lidia Ruiz-Moreno ${ }^{* * *}$
}

Resumo: As Diretrizes Curriculares Nacionais (DCN) para os cursos da saúde recomendam o ensino da promoção da saúde no sentido de adequar os currículos ao Sistema Único de Saúde (SUS). O objetivo deste estudo foi caracterizar o ensino da promoção da saúde em cursos de fonoaudiologia da cidade de São Paulo, identificando sua inserção curricular, estratégias educativas e mudanças propiciadas pelas DCN. A coleta de dados compreendeu análise documental dos planos de ensino e entrevistas com coordenadoras de cursos de fonoaudiologia. Os dados obtidos a partir dos planos de ensino foram sistematizados, considerando: denominação, inserção curricular, carga horária, objetivos, conteúdos e estratégias didáticas. Os núcleos que orientaram a análise temática das entrevistas foram concepções e mudanças curriculares. A promoção da saúde é abordada nas disciplinas em que predominam práticas tradicionais e, durante o estágio, em diferentes cenários de atuação. Na visão das coordenadoras, o ensino da promoção da saúde é relevante para a atuação do fonoaudiólogo no SUS, embora seja necessário incrementar o número de professores com experiência na área de saúde pública.

Palavras-chave: fonoaudiologia; promoção da saúde; educação superior; ensino.

\section{The teaching of health promotion in speech-language therapy graduate courses in the city of São Paulo}

Abstract: The National Curriculum Guidelines (NCG) for the courses on health recommend the teaching of health promotion in order to adapt curricula to the National Health System (NHS). The aim of this study was to characterize the teaching of health promotion in courses on speech-language therapy in the city of São Paulo, identifying its curricular insertion, educational strategies and changes offered by the NCG. Data collection consisted of documental review of teaching plans and interviews with coordinators of speech-language therapy courses. Data obtained from the teaching plans were systematized considering the name, curricular integration, teaching time, goals, content and teaching strategies. The nuclei that guided the thematic analysis of the interviews were conceptions and curriculum changes. Health promotion is taught in subjects with traditional practices and during internship, in different performance settings. In the coordinators' point of view, health promotion teaching is relevant for the

\footnotetext{
* Fonoaudióloga. isiscasanova@hotmail.com

** Professora da Universidade Federal do Amazonas, Brasil. alcidiamoraes@hotmail.com

**** Professora do Centro de Desenvolvimento do Ensino Superior em Saúde da Universidade Federal de São Paulo (Cedess/Unifesp), SP, Brasil. lidia.ruiz@unifesp.br
} 
insertion of a speech therapist in the NHS, although it is necessary to increase the number of experienced teachers in the public health area.

Key words: speech-language therapy; health promotion; higher education; teaching.

\section{Promoção da saúde: conceitos e práticas}

A promoção da saúde tornou-se amplamente conhecida e disseminada por meio das conferências internacionais dos anos de 1986 a 1997 (Ottawa, 1986; Adelaide, 1988; Sundswal, 1991; e Jakarta, 1997), que estabeleceram suas bases conceituais e políticas. A promoção da saúde compreende um campo conceitual teórico-prático que envolve mudanças profundas em valores sociais, culturais e políticos e implica um processo de transformação da sociedade, dos trabalhadores da saúde e do fomento às políticas públicas (Buss, 1999). Compreende também um processo de conscientização da comunidade para atuar na melhoria da qualidade de vida, incluindo a sua participação no controle desse processo; segundo esse entendimento, ela não é responsabilidade exclusiva do setor da saúde e vai além de um estilo de vida saudável, na direção do bem-estar social (Brasil, 2001).

No Brasil, a 8a Conferência Nacional de Saúde (CNS), em 1986, defendeu a descentralização da saúde e a implantação de políticas sociais para melhorar as condições de vida da população. No relatório final, expressaram-se os fundamentos da nova proposta de saúde, numa perspectiva ampliada e democrática, considerada fundamental para uma sociedade saudável, o que marcou a implantação do Sistema Único de Saúde (SUS), em 1988.

De acordo com a Lei Federal Brasileira no 8080, de 1990, a saúde tem diversos fatores determinantes, como: alimentação, moradia, saneamento básico, meio ambiente, trabalho, renda, educação, transporte, lazer e acesso a bens e serviços essenciais. De fato, a saúde não é somente a ausência de doença, mas o resultado dos vários fatores que condicionam a vida cotidiana, pelo que demanda um conjunto de políticas públicas direcionadas às necessidades da população.

No SUS, a estratégia de promoção da saúde é retomada como uma possibilidade de enfocar os aspectos que determinam o processo saúde-adoecimento em nosso país. Açôes sobre violência, desemprego, subemprego, saneamento básico, habitação, acesso à educação, fome, urbanização, qualidade do ar e da água representam estratégias adequadas que potencializam formas mais amplas de intervenção na saúde (Brasil, 2006).

Assim, promover a saúde implica ações amplas, integrais e intersetoriais direcionadas a indivíduos, grupos de sujeitos, comunidades e seu entorno, 
orientadas pelas concepções de sujeito social e de valorização do saber e da cultura popular, do processo saúde-doença relacionado à historicidade, à cultura e às condiçốes de vida das comunidades. Nessas ações, é necessário considerar a educação como um processo democrático, participativo, dialógico e transformador de estilos de vida.

\section{Fonoaudiologia e promoção da saúde}

Considerar os marcos conceituais da promoção da saúde envolve refletir sobre a atuação dos profissionais da saúde no exercício de uma prática humanizada e interdisciplinar, na tentativa de superar o modelo tecnicista da assistência. A formação desses profissionais tem que estar articulada com as políticas de saúde pública, no sentido de desenvolver competências para atuar no SUS.

Considerando a saúde integral como direito de todos e dever do Estado, a assistência fonoaudiológica, que inicialmente oferecia um atendimento clínico e individual, gradativamente foi aumentando sua inserção nos serviços públicos de saúde. Nesse processo, a fonoaudiologia buscou, inicialmente, os principais fundamentos para sua atuação na Medicina Preventiva, a qual definiu como "a ciência e a arte de evitar doenças, prolongar a vida, promover a saúde física e mental e a eficiência" (Leavell; Clark, 1976, p. 7). Nessa perspectiva, as práticas fonoaudiológicas tinham como princípio primordial evitar a perda da saúde e a invalidez depois que o homem foi afetado pela doença, além de protegê-lo de agentes patológicos.

Segundo Masson (1995), a incorporação direta do modelo da História Natural da Doença, de Leavell e Clark, à fonoaudiologia evidenciou uma preocupação com a relação entre os fatores etiológicos e as doenças fonoaudiológicas. Quanto à proteção da saúde, as açôes eram dirigidas para o combate a determinadas afecçōes, segundo suas características e necessidades específicas.

Embora focada na doença, a área da fonoaudiologia foi incorporando conceitos ligados a aspectos preventivos mais abrangentes. Os cursos de graduação em fonoaudiologia no Brasil, na década de 1980, começaram a incluir disciplinas relacionadas à prevenção dos distúrbios da comunicação. Porém, o campo da prevenção e promoção de saúde aparecia ainda de forma incipiente nesse período, demandando uma maior compreensão de conceitos e práticas para atuar com a população. Ao conceber a promoção da saúde como proteção específica de determinadas doenças, o modelo da fonoaudiologia preventiva continuava tendo a doença como objeto de ação, concebendo as medidas mais amplas fora do campo de atuação do fonoaudiólogo (Masson, 1995).

Na perspectiva de Penteado e Servilha (2004), a promoção da saúde implica açôes, integrais e intersetoriais, direcionadas a indivíduos, a grupos de sujei- 
tos, a comunidades e seu entorno, que valorizam o saber da comunidade e o processo participativo e transformador que envolve a inserção do fonoaudiólogo na saúde pública.

No atual cenário de mudanças no sistema de saúde e nas Instituições de Ensino Superior (IES), a área da fonoaudiologia tem refletido sobre a formação profissional e a atuação no SUS, dialogando com outras áreas em busca de conhecimentos que possam referendar suas ações. A inserção do fonoaudiólogo nos serviços de saúde pública, nos anos 1980, levou alguns autores a rever conceitos e práticas e a aprofundar as discussōes sobre sua atuação profissional, tradicionalmente voltada ao atendimento individual e curativo. Embora os primeiros cursos de fonoaudiologia tivessem surgido na década de 1960, apenas em 1981 a profissão foi reconhecida pela Lei no 6.965/81, a qual define, como competência do profissional habilitado, o desenvolvimento do trabalho de prevenção, no que se refere à área da comunicação escrita e oral, da voz e da audição.

$\mathrm{Na}$ década de 1990, a valorização da presença do fonoaudiólogo nas equipes multiprofissionais de promoção da saúde no serviço público demandou uma maior qualificação desse profissional para atuar na atenção primária. $\mathrm{O}$ estudo realizado por Chun (2004), ao analisar o fazer fonoaudiológico na década de 1990, mostrou que as práticas vigentes, com frequência, apresentavam-se distanciadas da realidade dos processos de saúde e adoecimento da população, dificultando o acesso do usuário à assistência fonoaudiológica nos serviços públicos. A incursão da fonoaudiologia na saúde pública, seja no que diz respeito a questões conceituais, seja na análise e sistematização de experiências no cotidiano, é ainda muito recente e pouco desenvolvida.

Marin et al. (2003) enfatizam que a atuação fonoaudiológica nos serviços públicos de saúde, historicamente restrita à clínica particular e marcada por práticas assistencialistas e reabilitadoras, implica não só uma mudança de cenário como também uma mudança conceitual que demanda adequação das instituições de ensino superior às políticas públicas de educação e saúde.

À semelhança de outros cursos da área da saúde, a formação do fonoaudiólogo foi influenciada pelo modelo biomédico, com visão restrita do processo saúdedoença e com currículo organizado em disciplinas isoladas, no qual o estudante é levado a especializar-se precocemente. Mudanças nesse processo formativo requerem que os currículos adotem perspectivas interdisciplinares e possam deslocar o eixo de formação, centrado na assistência individual, para um processo de formação contextualizado, considerando as dimensões sociais, econômicas e culturais da população, instrumentalizando os profissionais para enfrentar os problemas da população em diferentes cenários. Exercer a fonoaudiologia no âmbito da saúde pública significa inserir o profissional no Sistema Único de Saúde, em hospitais, unidades básicas, ambulatórios de es- 
pecialidades e postos de saúde (Dahan, 2001). Isso implica estimular uma atuação multiprofissional que respeite os princípios do controle social, as diretrizes do SUS e que atue com responsabilidade integral sobre a população num determinado território (Rede Unida, 1998).

O profissional com perfil generalista, capaz de identificar as questōes fonoaudiológicas de maior relevância na sua comunidade de abrangência, bem como de adotar medidas preventivas e de promoção da saúde cabíveis, pode prestar um atendimento de qualidade à população (Befi, 1997). Nos cursos de graduação em fonoaudiologia, o conhecimento sobre a saúde pública tem sido incluído como um campo de estudo. Porém, na prática profissional, o fonoaudiólogo ainda se caracteriza por desenvolver, com a população, treinamentos predominantemente técnicos, limitados e não sequenciais.

De acordo com as Diretrizes Curriculares Nacionais (2002), o curso de graduação em fonoaudiologia tem que formar profissionais capazes de atuar com qualidade, eficiência e resolutividade no SUS. Segundo esse documento, o fonoaudiólogo deve estar apto a desenvolver ações de prevenção, promoção, proteção e reabilitação da saúde, em nível tanto individual como coletivo.

Nesse contexto, o objetivo deste trabalho foi caracterizar o ensino da promoção da saúde em cursos de fonoaudiologia da cidade de São Paulo, identificando sua inserção curricular, as estratégias de ensino-aprendizagem e avaliação e as mudanças propiciadas pelas DCN.

\section{O estudo: onde e com quem?}

Este trabalho apresenta parte dos resultados da tese defendida no Programa de Mestrado "Ensino em Ciências da Saúde", do Centro de Desenvolvimento do Ensino Superior em Saúde da Universidade Federal de São Paulo (CEDESSUNIFESP). A investigação, de caráter exploratório-descritivo, com abordagem qualitativa (Minayo, 2004), foi realizada na cidade de São Paulo, em seis cursos de fonoaudiologia. As IES que fizeram parte deste estudo compreenderam duas instituições públicas (uma estadual e uma federal); quatro instituiçôes privadas (duas confessionais filantrópicas, uma filantrópica e uma privada, no sentido restrito). O projeto de pesquisa foi aprovado pelo Comitê de Ética (Processo: 0257/06), tendo sido cumpridos todos os procedimentos éticos estabelecidos.

A coleta de dados envolveu a análise documental dos planos de ensino das disciplinas e dos estágios supervisionados, para verificar a existência ou não de conteúdos de promoção da saúde. Esses dados foram sistematizados, considerando: denominação, momento de inserção curricular, carga horária, objetivos, conteúdos, estratégias de ensino e avaliação. 
Esse levantamento compreendeu também entrevistas com seis coordenadoras dos cursos referidos, identificadas neste trabalho de C1 a C6. Entendemos que, nessa função, as coordenadoras detinham informações de ordem administrativa, curricular e pedagógica que contribuíram para atingir os objetivos desta pesquisa.

As entrevistas foram submetidas à análise temática (Minayo, 2004). Após a gravação, os dados coletados passaram pelas seguintes etapas: transcrição textual das entrevistas, pré-análise do material coletado, leitura e releitura das transcrições, sistematização das respostas dos sujeitos, conforme os seguintes núcleos temáticos: a) concepções sobre o ensino da promoção da saúde e b) mudanças curriculares no ensino da promoção da saúde propiciadas pelas DCN.

\section{Resultados e discussão}

A idade das coordenadoras participantes deste estudo, todas do sexo feminino, variou entre 48 e 59 anos. Já, seu tempo de formação acadêmica como fonoaudiólogas oscilou de 18 a 34 anos, o que pode ser indicativo de vasta trajetória e de experiência profissional. O tempo de atuação docente das entrevistadas esteve entre 15 e 34 anos, e o período de coordenação no curso de fonoaudiologia variou de 3 meses a 11 anos. Apenas uma das coordenadoras não exercia a função de docente e as demais acumulavam as duas funções. Cabe ressaltar que todas as coordenadoras obtiveram o título de doutor, sendo quatro nas Áreas Específicas da fonoaudiologia, uma em Psicologia Experimental e outra em História e Filosofia da Educação.

\section{Ensino da promoção da saúde}

A análise dos planos de ensino permitiu identificar que o conteúdo sobre promoção da saúde está inserido em diferentes momentos curriculares, tanto nas disciplinas como nos estágios supervisionados, o que pode indicar o crescente compromisso das IES com os movimentos de mudança propiciados pelas atuais Diretrizes Curriculares para os cursos da área da saúde em consonância com o SUS. As disciplinas que abordam esse conteúdo, todas de caráter obrigatório, estão inseridas entre o $2^{\circ}$ e $3^{\circ}$ anos do curso. No entanto, em uma das instituições, a inserção acontece já desde o $1^{\circ}$ ano, o que indica um tratamento transversal do tema durante o curso. Existe grande diversidade da carga horária destinada ao ensino da promoção da saúde nos seis cursos estudados, variando entre 30 e 80 horas. O Quadro I apresenta as denominaçōes, o momento de inserção curricular e a carga horária das disciplinas que abordam o conteúdo promoção da saúde nos cursos de fonoaudiologia. 


\begin{tabular}{|c|c|c|c|}
\hline $\begin{array}{l}\text { Curso de } \\
\text { fonoaudiologia }\end{array}$ & $\begin{array}{l}\text { Disciplinas que } \\
\text { abordam conteúdos } \\
\text { de promoção da } \\
\text { saúde }\end{array}$ & $\begin{array}{l}\text { Momento de inserção } \\
\text { curricular }\end{array}$ & $\begin{array}{l}\text { Carga horária / } \\
\text { semestre (horas) }\end{array}$ \\
\hline C1 & $\begin{array}{l}\text { Fonoaudiologia em } \\
\text { saúde coletiva I e II }\end{array}$ & $\begin{array}{c}3^{\circ} \text { ano } \\
\left(5^{\circ} \text { e } 6^{\circ} \text { semestres }\right)\end{array}$ & 80 \\
\hline C2 & $\begin{array}{l}\text { Fundamentos em } \\
\text { saúde pública/ e } \\
\text { fonoaudiologia em } \\
\text { saúde pública }\end{array}$ & $\begin{array}{c}1^{\circ} \text { e } 3^{\circ} \text { anos } \\
\left(2^{\circ} \text { e } 4^{\circ} \text { semestres }\right)\end{array}$ & 80 \\
\hline C3 & $\begin{array}{l}\text { Fonoaudiologia na } \\
\text { perspectiva da } \\
\text { promoção da saúde }\end{array}$ & $\begin{array}{c}2^{\circ} \text { ano } \\
\left(3^{\circ} \text { semestre }\right)\end{array}$ & 60 \\
\hline $\mathrm{C} 4$ & $\begin{array}{l}\text { Promoção da saúde e } \\
\text { prevenção em } \\
\text { fonoaudiologia }\end{array}$ & $\begin{array}{c}3^{\circ} \text { ano } \\
\left(5^{\circ} \text { semestre }\right)\end{array}$ & 60 \\
\hline C5 & $\begin{array}{l}\text { Fonoaudiologia social } \\
\text { e preventiva }\end{array}$ & $\begin{array}{c}2^{\circ} \text { ano } \\
\left(1^{\circ} \text { semestre }\right)\end{array}$ & 30 \\
\hline C6 & $\begin{array}{l}\text { Introdução à saúde } \\
\text { pública }\end{array}$ & $\begin{array}{c}3^{\circ} \text { ano } \\
\left(2^{\circ} \text { semestre }\right)\end{array}$ & 45 \\
\hline
\end{tabular}

Fonte: Planos de ensino das disciplinas que abordam conteúdo de promoção da saúde nos cursos de fonoaudiologia.

Quadro I: Disciplinas que abordam conteúdos de promoção da saúde nos cursos de fonoaudiologia pesquisados da cidade de São Paulo

Embora existam diferentes denominações para as disciplinas que abordam a promoção da saúde, a análise dos planos de ensino mostrou semelhanças nos objetivos e nos conteúdos, os quais apresentam uma visão abrangente do processo de saúde/doença e buscam ampliar o nível de atuação profissional do fonoaudiólogo. As propostas educativas analisadas evidenciam que o fonoaudiólogo, como profissional da saúde, precisa compreender as condiçóes de saúde da população para atuar na promoção da saúde, na prevenção, na recuperação, sem desconsiderar os significativos avanços da fonoaudiologia, já consolidados, na área da reabilitação.

Os objetivos e os conteúdos explicitados nos planos de ensino das disciplinas que abordam a promoção da saúde abrangem questôes sociais, comunitárias, educacionais, com ênfase em açôes preventivas, embora exista maior preocupação com a dimensão cognitiva, sendo secundarizados os aspectos procedimentais e atitudinais. 
A análise dos planos de ensino apontou que, durante o desenvolvimento das disciplinas que abordam conteúdos relacionados à promoção da saúde, as estratégias de ensino utilizadas por todos os cursos correspondem a aulas expositivas, seminários, leitura de textos e exposição dialogada. Metodologias ativas e palestras ministradas por convidados acontecem em três cursos, e dinâmicas de grupo e vivências dos alunos em contato com a comunidade, durante os estágios curriculares, ocorrem em quatro cursos.

A aula expositiva é frequentemente utilizada para transmitir o conteúdo teórico. O uso habitual dessa estratégia, verificado neste estudo, pode ser um indicativo de um ensino reprodutivo, centrado no professor, predominante no Ensino Superior brasileiro (Batista; Batista, 2004; Masetto, 2003; Sonzogno, 2004). Porém, a aula expositiva na sua modalidade dialógica pode comportar a expressão de ideias para promover a construção do conhecimento e facilitar as interações interpessoais com o objeto de conhecimento (Lopes, 2001). Sonzogno (2004) defende a necessidade de mudanças no processo de ensino e aprendizagem, nas quais o professor assume o lugar de sujeito que ensina e também o lugar de quem aprende, mediando o processo. $\mathrm{O}$ aluno precisa desenvolver autonomia e responsabilidade na busca ativa de conhecimento e estar comprometido com seu processo de ensino-aprendizagem. Para Magnarelli et al. (2009), desenvolver estratégias inovadoras aumenta a motivação do aluno e seu envolvimento durante sua formação. Ruiz-Moreno et al. (2005) relatam que estratégias baseadas em aspectos da realidade dos participantes podem ajudar a valorizar os conhecimentos prévios dos sujeitos, possibilitar a reorganização do conhecimento, ampliar a reflexão crítica e o compromisso individual e social dos profissionais da área da saúde, já que os conteúdos são trabalhados nas esferas cognitiva, atitudinal, emocional, ético-política e das habilidades.

Quanto aos recursos didáticos para ministrar aulas expositivas e seminários, em todos os cursos de fonoaudiologia pesquisados, utilizam-se recursos audiovisuais, como projetor digital e vídeos. Sabe-se que o uso adequado de recursos didáticos no processo de comunicação pode facilitar o aprendizado. Porém, em nossa pesquisa, constatamos que apenas um curso de fonoaudiologia utiliza novas tecnologias de informação e comunicação (NTIC) para disponibilizar materiais de estudo aos alunos, organizar ligas e atividades grupais. Esse recurso pode ser uma motivação a mais para aprender, contribuindo para a democratização dos conhecimentos e desenvolvendo a autonomia, mas requer postura crítica e reflexiva, para a escolha do modelo pedagógico a ser adotado, no sentido de superar as práticas de ensino tradicionais, nas quais se reproduz, no espaço virtual, o modelo transmissivo de informações (RuizMoreno et al., 2008).

Masetto (2003) acrescenta que as NTIC podem ser utilizadas de modo a valorizar a autoaprendizagem, incentivar a formação permanente, a pesquisa 
de informações, o debate, a discussão, o registro de documentos, a elaboração de trabalhos, a construção da reflexão pessoal, a construção de artigos e textos, além de professor e aluno poderem trabalhar conjuntamente, de forma colaborativa.

Quanto aos cenários de ensino-aprendizagem privilegiados nas disciplinas que abordam o conteúdo de promoção da saúde, a sala de aula ainda é o espaço mais usado para desenvolver as atividades didáticas.

Os dados coletados evidenciam que a avaliação da aprendizagem prioriza as provas, relacionadas ao conteúdo teórico desenvolvido, aplicadas no final da disciplina, caracterizando uma modalidade somativa de avaliação, com vistas à aprovação/reprovação do aluno (Seiffert, 2005).

Nos planos de ensino dos cursos de fonoaudiologia pesquisados, o ensino da promoção da saúde acontece também nos estágios supervisionados, durante o $3^{\circ}$ e $4^{\circ}$ anos (Quadro II). Segundo as Diretrizes Curriculares, o estágio curricular "deve ocorrer, prioritariamente, nos dois últimos anos de formação. A maioria destas atividades deve ser realizada na clínica-escola, adequadamente equipada para tal finalidade." (Brasil, 2002, p. 3).

\begin{tabular}{|c|l|c|}
\hline Curso de fonoaudiologia & $\begin{array}{l}\text { Estágio supervisionado que aborda a } \\
\text { promoção da saúde }\end{array}$ & Ano de inserção \\
\hline C1 & Saúde coletiva I e II & $4^{\circ}$ \\
\hline C2 & $\begin{array}{l}\text { Saúde pública } \\
\text { Instituições }\end{array}$ & $3^{\circ}$ e $4^{\circ}$ \\
\hline C3 & $\begin{array}{l}\text { Audiologia do trabalho I e II } \\
\text { fonoaudiologia: Programa } \\
\text { creche e programa escola } \\
\text { atenção 1 em audiologia I e II } \\
\text { fonoaudiologia I e II }\end{array}$ & $3^{\circ}$ e $4^{\circ}$ \\
\hline C4 & $\begin{array}{l}\text { Fonoaudiologia educacional- } \\
\text { programa de intervenção } \\
\text { introdução à audiologia clínica } \\
\text { prática }\end{array}$ & $3^{\circ}$ e $4^{\circ}$ \\
\hline C5 & $\begin{array}{l}\text { Fonoaudiologia } \\
\text { fonoaudiologia clínica }\end{array}$ & $3^{\circ}$ e $4^{\circ}$ \\
\hline C6 & $\begin{array}{l}\text { Fonoaudiologia em serviços de } \\
\text { saúde pública }\end{array}$ & $3^{\circ}$ e $4^{\circ}$ \\
\hline
\end{tabular}

Fonte: Planos de ensino dos estágios curriculares dos cursos de fonoaudiologia.

Quadro II: Estágio supervisionado que aborda promoção da saúde e ano de inserção nos cursos de fonoaudiologia pesquisados 
As Diretrizes Curriculares (Brasil, 2002) norteiam a elaboração dos currículos das IES, no sentido de garantir a qualidade da formação oferecida aos estudantes, preparando o futuro graduado para enfrentar os desafios das rápidas transformaçóes da sociedade, do mundo do trabalho e das condiçôes do exercício profissional.

As políticas de saúde e educação na área da saúde são consideradas, pelas coordenadoras dos cursos de fonoaudiologia participantes deste estudo, aspectos importantes nos movimentos de mudança institucional, como se evidencia na seguinte fala: "Sem dúvida a questão das diretrizes, a questão da politica do SUS, todas as discussōes que têm ocorrido em termos de saúde pública no país e até de fazer vingar as políticas, é sem dúvida o que está forçando uma reestruturação." (C2).

Indagada sobre as mudanças ocorridas no ensino da promoção da saúde a partir das DCN, uma das coordenadoras comentou que a criação do curso de fonoaudiologia, quase simultaneamente à implantação das Diretrizes Curriculares, trouxe como consequência a incorporação dessas normas desde o início: "As diretrizes já estavam prontas quando eu montei o curso, então ele já segue aquilo que as diretrizes falam." (C1).

A coordenadora de um curso de mais de 40 anos de existência comentou a adequação ao documento das Diretrizes Curriculares: "Fizemos uma reforma curricular, mais em função de trabalho com metodologia ativas, de integrar melhor $o$ aluno de vários niveis, integrar as turmas, desenvolver atividades programadas, multidisciplinares e interdisciplinares." (C 6).

As mudanças acontecidas em um dos cursos de fonoaudiologia, também já consolidado no momento do estabelecimento das Diretrizes Curriculares, sinalizaram adequações em aspectos mais pontuais:

Foi só a mudança do nome da disciplina Fonoaudiologia preventiva, passou para Fonoaudiologia na perspectiva da promoçāo da saúde, até para adequar mais o nome da disciplina ao conceito de como é vista a promoção da saúde. Nós já trabalhávamos um pouco com essa questão do ensino da promoção da saúde antes das diretrizes. (C3)

As entrevistadas C4 e C5, coordenadoras de cursos de fonoaudiologia, cuja origem, relacionada à área da saúde, revela serem eles influenciados pelos movimentos da medicina e enfermagem, valorizaram a influência das políticas públicas que objetivam mudanças nas IES:

Mudanças progressistas nos últimos anos têm ocorrido, sim. Elas têm ocorrido no sentido de acompanhar o que está acontecendo no contexto do Brasil, não é nem de escolha nossa, mas éobrigatório, 
com o projeto do AprenderSUS, VerSUS, que de certa forma trouxe algumas modificaçōes de formaçãao profissional [...] a inserção da saúde coletiva, do nosso curso que aconteceu junto com a medicina, eu acho que foi uma escolha muito feliz. (C4)

As transformações na área de saúde e no Ensino Superior também são elementos facilitadores para o ensino da promoção da saúde, na perspectiva desta coordenadora:

\section{[...] a grande mudança, o esforço de formar profissionais que possam atuar na promoção da saúde não chega pela fonoaudiologia, chega pela medicina ou enfermagem, eu acho que é muito bom, porque na nossa área tem gente mobilizada para fazer, para auxiliar nessa mudança. Não vai ser uma mudança muito fácil (C5).}

Segundo Maia (2004), as adequações do currículo às novas Diretrizes Curriculares podem resultar em modificaçōes pontuais ou na importação de modelos construídos em outros contextos e trilhados por outros indivíduos. $\mathrm{O}$ autor ressalta a importância de o currículo ser elaborado coletivamente, considerando a especificidade da área e a inserção histórica e social da instituição.

Masetto (2003) entende currículo como um conjunto de conhecimentos, saberes, competências, habilidades, experiências, vivências e valores que os alunos precisam adquirir e desenvolver de maneira integrada e explícita, mediante práticas e atividades de ensino-aprendizagem. É importante levar em consideração as características do curso de fonoaudiologia, sua origem ligada à área da educação ou da saúde e suas necessidades, bem como os interesses dos alunos e do meio social.

$\mathrm{Na}$ ótica da entrevistada $\mathrm{C} 2$, de fato as mudanças curriculares têm promovido uma valorização da formação de fonoaudiólogo que amplia sua atuação em saúde pública: "[...] no currículo anterior já tinha parte teórica e tinha estágios, mas não especificos, mas agora no currículo novo a gente acrescentou um estágio específico em saúde pública já no sexto semestre." (C2).

Segundo Maia (2004, p. 117), o ensino das atividades práticas, em geral, ocorre nos momentos finais dos cursos, partindo-se do pressuposto de que "primeiro é necessário saber, para depois fazer". O autor refere que essa premissa atualmente é criticada, uma vez que a prática pode, e deve, ser problematizada para estimular o processo de ensino-aprendizagem do aluno. Diante de uma determinada situação da realidade, a proposta educativa precisa buscar a integração dos aspectos teóricos e práticos necessários à compreensão ou à proposição de soluções.

Antecipar a inserção dos alunos em cenários de prática profissional, de forma problematizadora, pode desenvolver o raciocínio, instigar a curiosidade e a 
busca constante do conhecimento em novos contextos. A problematização preconizada por Paulo Freire (1996) envolve a atitude de crítica da realidade que leve a atribuir significados, o que propicia a aprendizagem e a atitude transformadora da realidade. O autor afirma que "[...] o exercício da curiosidade convoca a imaginação, a intuição, as emoções, a capacidade de conjecturar, de comparar, na busca da perfilização do objeto ou do achado de sua razão de ser."(Ibidem, p. 88).

As Diretrizes Curriculares recomendam a utilização de experiências reais a serem vivenciadas pelos estudantes para a compreensão e a proposição de soluções. Em nossa pesquisa, uma instituição privada citou diversos cenários da práxis fonoaudiológica, como unidades básicas de saúde, hospitais, creches, escolas públicas e a própria clínica-escola do curso de fonoaudiologia. Em duas instituições, os alunos realizam visitas domiciliares e, em uma outra, participam de atividades do Programa de Saúde da Família (PSF). Contudo, as coordenadoras de IES privadas referiram limitaçôes no desenvolvimento desses estágios, principalmente ao estabelecer parcerias com as Secretarias Municipais de Saúde e Educação para contar com os cenários de prática.

Rodrigues, Rezende e Marchiori (2003) comentam que a fonoaudiologia cresceu muito com a ampliação dos cenários de inserção. Em razão dessa expansão, surgiu o Documento Oficial 001/2002, referência para a fonoaudiologia no Brasil, que caracteriza as açōes inerentes ao exercício da profissão nos diferentes cenários de atuação do fonoaudiólogo: unidades básicas de saúde, ambulatórios de especialidades, hospitais e maternidades, consultórios, clínicas, home-care, atendimentos domiciliares, asilos e casas de saúde, creches e berçários, escolas regulares e especiais, instituições de Ensino Superior, meios de comunicação, empresas, associações e organizaçóes não governamentais.

É interessante destacar que a maioria das coordenadoras participantes da pesquisa considera que as atuais Diretrizes Curriculares, ao proporem a diversificação de estratégias e cenários, possibilitam ampliar a abordagem das questóes sociais, das necessidades atuais da população, do mundo do trabalho, da política do SUS, adequando a formação do fonoaudiólogo às novas exigências profissionais. Consideram que a aproximação a cenários de prática profissional durante os cursos, que incluem serviços de saúde, escolas, comunidade, constitui um relevante aspecto formativo na área da saúde. Contudo, as coordenadoras relatam que um entrave para efetivar esse processo de formação é a escassez de professores fonoaudiólogos com experiência na área de saúde pública.

No atual contexto, existe uma maior possibilidade de repensar, de discutir uma composição curricular atualizada para a formação de um profissional crítico e reflexivo, mas certas condições precisam ser atendidas neste momento em que a sociedade se volta para obter seu direito à saúde, principalmente no 
que diz respeito aos aspectos preventivos e de promoção à saúde, reconhecendo-se como sujeito das mudanças de seus padrôes de vida.

\section{Considerações finais}

Em concordância com as DCN, existem avanços na inserção curricular da promoção da saúde nos cursos de fonoaudiologia estudados na cidade de São Paulo. Nos planos de ensino de todos os cursos existe, ao menos, uma disciplina que detalha objetivos e conteúdos que apresentam uma visão abrangente do processo da saúde e da doença e buscam ampliar o nível de atuação profissional do fonoaudiólogo. Porém existe maior ênfase na dimensão teórica e no desenvolvimento de habilidades cognitivas. As estratégias didáticas mais frequentes, descritas nos planos de ensino, são as aulas expositivas para transmissão de conhecimentos teóricos, e a prova aplicada no final do processo é a prática mais comum, o que caracteriza uma avaliação somativa.

A predominância do modelo pedagógico tradicional, com centralidade no professor e dicotomia teórico-prática, presente nas disciplinas contrasta com a diversificação de cenários de inserção profissional explicitada nos planos de ensino dos estágios supervisionados. Os objetivos e os conteúdos de aprendizagem nessa etapa privilegiam a dimensão procedimental e a atitudinal relacionadas ao desenvolvimento de competências específicas do fonoaudiólogo. A atuação em equipes multiprofissionais, em diferentes níveis de assistência, e a formação humanista do fonoaudiólogo são enfatizadas nos planos de ensino, durante o desenvolvimento dos estágios supervisionados. Mas a inserção precoce dos alunos em cenários de prática ainda não parece ser uma realidade de todos os cursos pesquisados. Consideramos que propostas curriculares que contemplem diversificação de cenários, desde o início do curso, podem contribuir para a formação profissional do fonoaudiólogo, possibilitando maior abrangência de atuação profissional.

Nos movimentos ocorridos nas propostas curriculares após as Diretrizes Curriculares, as coordenadoras dos cursos de fonoaudiologia relataram desde mudanças pontuais, como a alteração do nome da disciplina e a readequação da carga horária, até aspectos mais amplos, que envolveram diversificação de cenários de aprendizagem durante o estágio supervisionado. Na visão das coordenadoras, a inserção em unidades básicas de saúde, escolas e creches contribui para a adequação do perfil profissional do fonoaudiólogo para atender as demandas sociais. Dispor de professores com experiência em saúde pública, capazes de desenvolver propostas inovadoras e motivar os alunos para atuação nesse contexto, parece ser uma dificuldade na tarefa de ampliar a inserção do ensino da promoção da saúde nos cursos de fonoaudiologia. 
Deparamo-nos com coordenadoras comprometidas com o processo de mudança curricular e a formação do fonoaudiólogo, acordes com o atual contexto político e social; que reconhecem suas limitaçōes, mas procuram superá-las e transformá-las. Existe o entendimento, por parte das coordenadoras, de que o ensino da promoção da saúde é relevante para a inserção do fonoaudiólogo no Sistema Único de Saúde nos diferentes níveis de assistência, contemplando sua atuação nas equipes multiprofissionais.

Discussóes amplas, que envolvam todos os atores que participam do planejamento do Projeto Político Pedagógico das IES, precisam ser aprofundadas na área da fonoaudiologia. A transversalidade do ensino da promoção da saúde, a relação ensino-pesquisa-assistência e a formação de professores capazes de diversificar estratégias, utilizar novas tecnologias de informação e comunicação e novos cenários de atuação são aspectos a serem atendidos na formação profissional do fonoaudiólogo, assim como o desenvolvimento de competências que atendam as necessidades sociais, a dimensão cuidadora e o entendimento do processo saúde-doença, considerando os determinantes biológicos, psicológicos e sociais desde o início do curso, na tentativa de articular conceitos e práticas.

Assim, compartilhamos das reflexões de Batista e Batista (2004), no âmbito dos cursos da saúde: um dos condicionantes mais importantes na formação do profissional em saúde têm sido as Diretrizes Curriculares. Ao inovar, trazem um perfil comum à área da saúde e indicam que os currículos de graduação devem atentar para a questão da humanização e da ética; do aluno como sujeito do conhecimento; da problematização como estratégia metodológica privilegiada; da integração dos currículos com o Sistema Único de Saúde (SUS); da educação permanente como instrumento em um contexto de tantas e tão significativas transformaçôes econômicas, políticas e educacionais. Nesse sentido, a utilização de metodologias ativas de ensino-aprendizagem, o uso crítico-reflexivo de NTIC, a incorporação de conteúdos relativos à saúde pública, a participação de docentes em eventos formativos e o envolvimento em programas do Ministério da Saúde, em parceria com o da Educação, são indicadores da ativação de mudanças nos cursos de fonoaudiologia.

\section{Referências bibliográficas}

BATISTA, Nildo Alves; BATISTA, Sylvia Helena. Introdução à docência em saúde: desafios e perspectivas. In: BATISTA, Nildo Alves; BATISTA, Sylvia Helena (Org.). Docência em saúde: temas e experiências. São Paulo: Senac, 2004. 283 p.

BEFI, Débora Lopes. Fonoaudiologia na atenção primária à saúde. In: BEFI, Débora Lopes (Org.). Fonoaudiologia na atenção primária à saúde. São Paulo: Lovise, 1997. 199 p. v. 3. 
BRASIL. Ministério da Saúde. Carta de Otawa. Brasília, DF: Ministério da Saúde, Projeto Promoção da Saúde, 2001. 112 p.

BRASIL. Ministério da Educação e Cultura (MEC). Resolução CNE/CES. 5/2002. Brasília, DF: Conselho Nacional de Educação, 19 fev. 2002. p. 5.

BRASIL. Ministério da Saúde. Política Nacional da Promoção da Saúde. Brasília, DF: Ministério da Saúde, 2006. 48 p.

BUSS, Paulo Marchiori. Promoção e educação em saúde no âmbito da Escola de Governo em Saúde da Escola Nacional de Saúde Pública. Cadernos de Saúde Pública, Rio de Janeiro, v. 15, p.177-185, 1999. supl. 2.

CHUN, Regina Yu Shon. Promoção de Saúde e as Práticas em Fonoaudiologia. In: FERREIRA, Leslie Piccoloto; BEFI, Débora Lopes (Org.). Tratado de Fonoaudiologia. São Paulo: Roca, 2004. 1104 p. Cap. 41.

DAHAN, Débora. Atuação fonoaudiológica em saúde pública: uma abordagem preventiva. 2001. Disponível em: <http//www.fonoaudiologia.com/trabalhos/artigos/artigo-026.htm>. Acesso em: 10 fev. 2007.

FREIRE, Paulo. Pedagogia da autonomia: saberes necessários à prática educativa. 30. ed. São Paulo: Paz e Terra, 1996. 146 p.

LEAVELL, Hugh Rodman; CLARK, Guarney. Medicina preventiva. Rio de Janeiro: Mc Graw-Hilll do Brasil, 1976. 684 p.

LOPES, Antonia Osima. Aula expositiva: superando o tradicional. In: VEIGA, Ilma Passos Alencastro (Org.). Técnicas de ensino: por que não? 12. ed. Campinas: Papirus, 2001. p. 35-48. $158 \mathrm{p}$.

MAGNARELLI, Gladis et al. El trabajo en pequeños grupos facilita la enseñanza- aprendizaje de Bioquímica em Medicina. Revista Brasileira de Educação Médica, Rio de Janeiro, v. 33, n. 3 , p. 374-381, jul./set. 2009.

MAIA, José Antonio. O currículo em ensino superior na saúde. In: BATISTA, Nildo Alves; BATISTA, Sylvia Helena (Org.). Docência em saúde: temas e experiências. São Paulo: Senac, 2004. 283 p.

MARIN, Carla Regina et al. Promoção da saúde em fonoaudiologia: açôes coletivas em equipamentos de saúde e de educação. Revista da Sociedade Brasileira de Fonoaudiologia, São Paulo, v. 8, n. 1, p. 35-41, 2003.

MASETTO, Marcos Tarcisio. Competência pedagógica do professor universitário. São Paulo: Summus, 2003. $194 \mathrm{p}$.

MASSON, Maria Lucia Vaz. É melhor prevenir ou remediar? Um estudo sobre a construção do conceito de prevenção em Fonoaudiologia. 1995.142 p. Dissertação (Mestrado em Distúrbios da Comunicação Humana) — Pontifícia Universidade Católica de São Paulo, São Paulo.

MINAYO, Maria Cecília Souza. O desafio do conhecimento: pesquisa qualitativa em saúde. 8. ed. São Paulo: Hucitec, 2004. 269 p. 
PENTEADO, Regina Zanella; SERVILHA, Emilse Aparecida Merlin. Fonoaudiologia em Sáude Pública/Saúde Coletiva: compreendendo prevenção e o paradigma da promoção da saúde. Distúrbios da Comunicação, São Paulo, v. 16, n. 1, p. 107-116, abr. 2004.

REDE UNIDA. Contribuição da Rede Unida para as novas Diretrizes Curriculares dos Cursos de Graduação da Área de Saúde. Olho Mágico, Londrina, v. 16, p. 11-28, 1998.

RODRIGUES, Viviane de Souza; REZENDE, Maria Teresa de Melo Carvalho; MARCHIORI, Luciana Lozza de Moraes. Estratégias para a implantação das diretrizes curriculares nacionais nos cursos de fonoaudiologia. Olho Mágico, Londrina, v. 10, n. 4, p. 55-60, out./dez. 2003.

RUIZ-MORENO, Lidia et al. Jornal vivo: um relato de uma experiência de ensino-aprendizagem na área da saúde. Interface: comunicação, saúde e educação, Botucatu, v. 9, n. 16, p. 195-204, fev. 2005.

RUIZ-MORENO, Lidia; PITTAMIGLIO, Silvia Elsa Lizarralde; FURUSATO, Meiry Akiko. Lista de discussão como estratégia de ensino-aprendizagem na pós-graduação em Saúde. Interface: comunicação, saúde e educação, Botucatu, v. 12, n. 27, p. 883-892, out./dez. 2008. Disponível em: <http://www.scielo.br/scielo.php>. Acesso em: 12 maio 2010.

SEIFFERT, Otília. A formação do enfermeiro: uma aproximação à recente produção científica (2001-2005). Trabalho, Educação e Saúde, Rio de Janeiro, v. 3, n. 3, set. 2005.

SONZOGNO, Maria Cecília. Metodologias no ensino superior: algumas reflexões. In: BATISTA, Nildo Alves; BATISTA, Sylvia Helena (Org.). Docência em saúde: temas e experiências. São Paulo: Senac, 2004. 283 p.

Recebido em 23 de setembro de 2009 e aprovado em 30 de junho de 2010. 